\title{
Transgenerational adaptation to heavy metal salts in Arabidopsis
}

\section{Mohammad Reza Rahavi, Zoë Migicovsky, Viktor Titov and Igor Kovalchuk*}

Department of Biological Sciences, University of Lethbridge, Lethbridge, AB, Canada

\section{Edited by:}

Shawn Kaeppler, University of Wisconsin-Madison, USA

\section{Reviewed by:}

Shawn Kaeppler, University of Wisconsin-Madison, USA Matteo Pellegrini, University of California Los Angeles, USA

Rajandeep Sekhon, University of Wisconsin-Madison, USA

${ }^{*}$ Correspondence:

Igor Kovalchuk, Department of Biological Sciences, University of Lethbridge, Lethbridge, AB, Canada T1K 3M4

e-mail:igor.kovalchuk@uleth.ca
Exposure to abiotic and biotic stress results in changes in plant physiology and triggers genomic instability. Recent reports suggest that the progeny of stressed plants also exhibit changes in genome stability, stress tolerance, and methylation. Here we analyzed whether exposure to $\mathrm{Ni}^{2+}, \mathrm{Cd}^{2+}$, and $\mathrm{Cu}^{2+}$ salts leads to transgenerational changes in homologous recombination frequency and stress tolerance. We found that the immediate progeny of stressed plants exhibited an increased rate of recombination. However, when the progeny of stressed plants was propagated without stress, recombination reverted to normal levels. Exposure of plants to heavy metals for five consecutive generations (S1-S5) resulted in recombination frequency being maintained at a high level. Skipping stress following two to three generations of propagation with $50 \mathrm{mM} \mathrm{Ni}^{2+}$ or $\mathrm{Cd}^{2+}$ did not decrease the recombination frequency, suggesting plant acclimation to upregulated recombination. Analysis of the progeny of plants exposed to $\mathrm{Cu}^{2+}$ and $\mathrm{Ni}^{2+}$ indicated higher stress tolerance to the heavy metal parental plants were exposed to. Tolerance was higher in plants propagated with stress for three to five generations, which resulted in longer roots than plants propagated on heavy metals for only one to two generations. Tolerance was also more prominent upon exposure to a higher concentration of salts. The progeny of stressed plants were also more tolerant to $\mathrm{NaCl}$ and methyl methane sulfonate.

Keywords: heavy metal salts, homologous recombination, stress tolerance, transgenerational response, Arabidopsis thaliana

\section{INTRODUCTION}

Stress exposure results in numerous physiological changes in plants (Wilkinson and Davies, 2010; Roy et al., 2011). Stresses that damage DNA directly or indirectly also lead to genetic changes in exposed and non-exposed somatic cells, (Kovalchuk et al., 2000; Filkowski et al., 2004; Boyko et al., 2010b) meiotic cells, and progeny (Lucht et al., 2002; Molinier et al., 2005; Boyko and Kovalchuk, 2010; Yao and Kovalchuk, 2011). These genetic changes, called mutations, are typically deleterious but may also contribute to useful genetic variability in individual plants. As such mutations are rare they are unlikely to contribute to the fitness of the entire population in a quick and meaningful way. However, plants are known to acclimate and adapt to stress in a fast and efficient manner (Boyko and Kovalchuk, 2011a,b; Mirouze and Paszkowski, 2011) and because the entire population of plants typically acquires a certain level of tolerance to stress, it is believed that the adaptive processes are partially dependent on epigenetic mechanisms (Boyko and Kovalchuk, 2011a,b; De Block and Van Lijsebettens, 2011; Mirouze and Paszkowski, 2011).

Several recent reports have demonstrated that in addition to higher stress tolerance the progeny of stressed plants also exhibit changes in DNA methylation and genome stability (Molinier et al., 2005; Boyko and Kovalchuk, 2008; Pecinka et al., 2009; Boyko et al., 2010a; Kathiria et al., 2010; Ito et al., 2011; Yao and Kovalchuk, 2011) which appear to be dependent on the function of short interfering (si)RNAs -regulated pathways. siRNAs are trans-acting epigenetic signals that can reversibly and in a sequence-specific manner modify gene expression at the transcriptional level (Carthew and Sontheimer, 2009; Malone and Hannon, 2009). These molecules are developmentally controlled but are also responsive to environmental stimuli. siRNAs can direct DNA methylation at asymmetric cytosines and influence distribution of modified histones, facilitating the recruitment of chromatin modifiers to specific genomic regions (Saze, 2008; Bourc'his and Voinnet, 2010). Small RNAs can also act as mobile signals during plant development (Chitwood et al., 2009; Dunoyer et al., 2010; Molnar et al., 2010), regulating the inheritance of epigenetic information during mitosis and meiosis via differential RNA pools in male and female gametes (Grant-Downton et al., 2009; Mosher et al., 2009; Slotkin et al., 2009). It is thus possible that siRNAs act as signals that establish transgenerational inheritance of stress tolerance in plants (Boyko and Kovalchuk, 2011a,b; Hauser et al., 2011). Grafting experiments using Dicer-like 2, 3, and 4 mutants allowed Molnar et al. (2010) to show that a mobile subset of DCL3/Pol IV-dependent 24-nucleotide sRNAs could direct epigenetic modifications in Arabidopsis (Molnar et al., 2010). The authors demonstrated a strong correlation between sRNA, methylated DNA, and transposons. Although no transgenerational work has been done, it was suggested that $24-n t$ siRNAs produced in the meristem allow plants to respond to activation of transposons in somatic cells, possibly reinforcing silencing of repetitive elements in pluripotent cells producing the next generation. Heat stress changed DNA methylation and histone modifications at repetitive elements and the control over transposon activity was also 
shown to be dependent on siRNA-mediated pathway (Ito et al., 2011).

Methylation changes such as hypo- and hypermethylation of various regions in stressed tissues occur in response to siRNAs or other signaling molecules. For example, exposure to heavy metals in hemp and clover lead to hypomethylation of several genomic loci (Aina et al., 2004), whereas response to water deficit in pea (Labra et al., 2002) and to viral infection in tomato (Mason et al., 2008) resulted in DNA hypermethylation. It is still unclear what happens in the progeny as there is only handful of papers which examine the changes in DNA methylation in the progeny of stressed plants. However, the progeny of Arabidopsis plants exposed to different abiotic stresses showed global genome hypermethylation with local areas of hypomethylation (Boyko et al., 2010a). In the progeny of infected tobacco plants, global hypermethylation was accompanied by the redistribution of DNA methylation from the nuclear center to the nuclear periphery (Kathiria et al., 2010). In contrast, an immediate and transgenerational release of transgene silencing in plants exposed to heat, cold, and UVB stresses was correlated with modifications in histone occupancy and acetylation of the histone $\mathrm{H} 3$ but not dependent on changes in DNA methylation (Lang-Mladek et al., 2010).

Exposure to many stresses including temperature, water, UVB, UVC, oxidative chemicals, salt, viral, and bacterial stress all result in somatic and transgenerational changes in homologous recombination frequency (HRF), point mutation frequency, and microsatellites stability (Kovalchuk et al., 2000; Ries et al., 2000; Lucht et al., 2002; Molinier et al., 2005; Van Der Auwera et al., 2008; Pecinka et al., 2009; Boyko et al., 2010a,b; Kathiria et al., 2010; Bollmann et al., 2011; Yao and Kovalchuk, 2011). In particular, changes in recombination frequency are important because homologous recombination is not only a repair mechanism that helps sustain genome stability but also the mechanism responsible for crossing over during meiosis, thus leading to genetic diversity. Studying the frequency of recombination across generations thus allows us to evaluate the repair capacity and ability to diversify the genome composition in a given plant population.

Previously, we found that the high frequency of homologous recombination and stress tolerance observed in the progeny of stressed plants subsided dramatically when these plants were propagated to next generation without stress (Boyko et al., 2010a). We thus decided to test whether continuous exposure to stress would result in the maintenance of elevated HRF. In addition, since no transgenerational experiments had been performed using heavy metals, we tested whether plants exposed to $\mathrm{Cu}^{2+}, \mathrm{Cd}^{2+}$, or $\mathrm{Ni}^{2+}$ for five consecutive generations would exhibit changes in HRF and stress tolerance. We found that the frequency of recombination was typically higher in plants propagated in the presence of stress for more generations. We also determined that propagation without stress following one or two generations of stress exposure causes a decrease in HRF. In contrast, when stress was skipped after three to four generations of exposure, HRF either did not decrease, as in case of treatments with $\mathrm{Cd}^{2+}$ or $\mathrm{Ni}^{2+}$, or the decrease was smaller as in case of treatment with $\mathrm{Cu}^{2+}$. Finally, the progeny of stressed plants exhibited higher tolerance to same stress as well as to $\mathrm{NaCl}$ and methyl methane sulfonate (MMS). The stress tolerance increased with each subsequent generation - fourth -fifth generations were more tolerant than first, second, and third generations of stressed plants.

\section{RESULTS \\ EXPOSURE TO $\mathrm{Cu}^{2+}, \mathrm{Cd}^{2+}$, AND Ni ${ }^{2+}$ TRIGGERED INCREASE IN SOMATIC HRF}

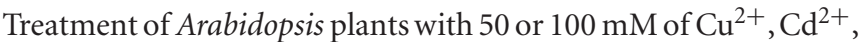
or $\mathrm{Ni}^{2+}$ resulted in an over twofold increase in somatic HRF. The highest increase was observed upon exposure to $\mathrm{Cu}^{2+}$, followed by $\mathrm{Cd}^{2+}$ and $\mathrm{Ni}^{2+}$ (Figure $\mathbf{1 A}$ ).

To test whether progeny of exposed plants also showed increased HRF, we propagated exposed and non-exposed plants to next generation (G1). The progeny of stressed plants were called "S1," whereas the progeny of control - "C1." We found S1 plants to have higher spontaneous HRF, a change that was more profound in response to $\mathrm{Cd}^{2+}$ and $\mathrm{Cu}^{2+}$ than $\mathrm{Ni}^{2+}$ (Figure 1B). In contrast to the G0 generation, the highest increase in somatic HRF of progeny was seen in plants exposed to $100 \mathrm{mM} \mathrm{Cd}^{2+}$.

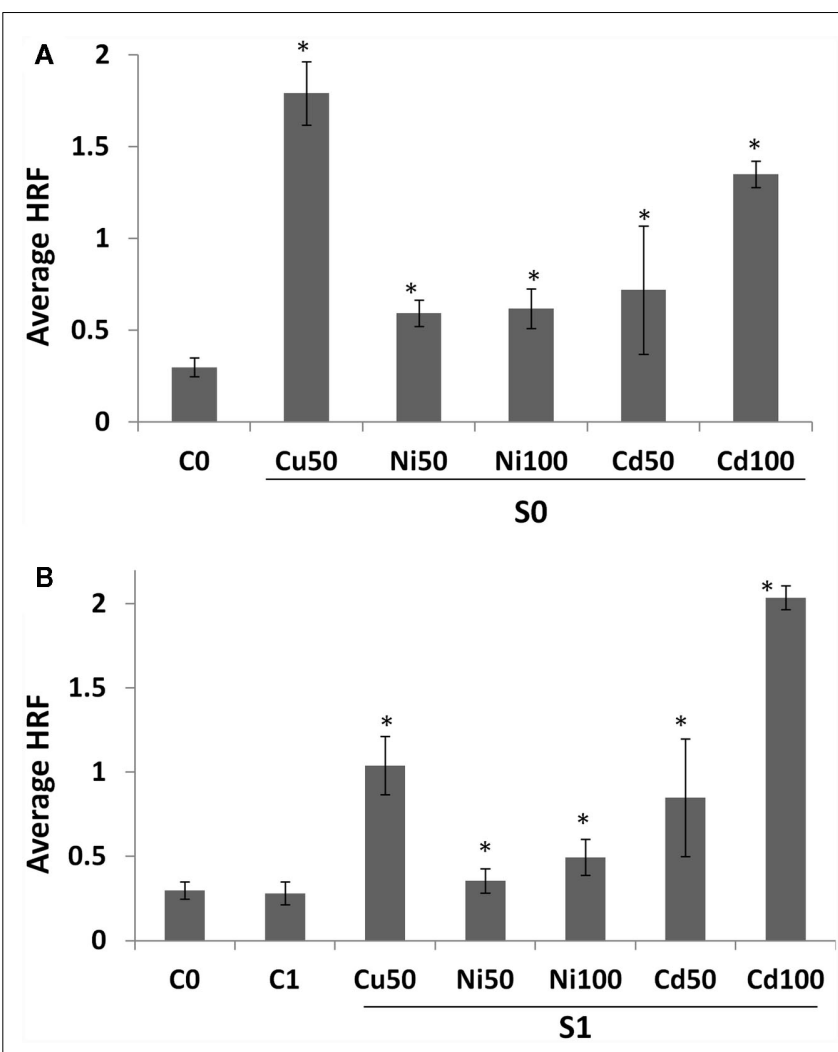

FIGURE 1 | Homologous recombination frequency (HRF) in somatic tissue and the progeny of stressed plants. (A) HRF is shown as an average of three independent experiments. Bars show SD. Asterisks indicate significant differences between individual treatment group and a control group (Student's t-test, $p<0.05$ in all cases). (B) HRF in the progeny of stressed and progeny of control plants (labeled as " $\mathrm{G} 1$ ") is shown as an average of three independent experiments. HRF in somatic tissue of non-exposed plants (CO) is shown for comparison. Bars show SD. Asterisks indicate significant differences in HRF between individual G1 group and G0 untreated plants (CO; Student's $t$-test, $p<0.05$ in all cases). No significant difference between $\mathrm{C} 0$ and $\mathrm{C} 1$ groups were found $(p>0.1)$. 


\section{CONTINUOUS EXPOSURE TO STRESS RESULTED IN AN EVEN HIGHER INCREASE IN HRF IN THE CONCURRENT PROGENY, WHEREAS SKIPPING STRESS EXPOSURE REVERTED THE TREND}

In past we have shown that propagating the progeny of plants exposed to stress (S1) without stress (S1C1) returns HRF to a level nearly equivalent to that observed in control plants (Boyko et al., 2010a). Therefore, we decided to test whether continuous exposure to stress would maintain a high HRF in the progeny. Arabidopsis plants were propagated for five generations (S1-S5) in the presence of 50 and $100 \mathrm{mM} \mathrm{Cu}^{2+}, \mathrm{Ni}^{2+}$, or $\mathrm{Cd}^{2+}$. To test if $\mathrm{HRF}$ would return to normal when plants are grown without stress, S1, S2, S3, and $\mathrm{S} 4$ plants were also propagated without stress and S1C1, S2C1, $\mathrm{S} 3 \mathrm{C} 1$, and $\mathrm{S} 4 \mathrm{C} 1$ generations were obtained (Figure 2). In order to determine whether skipping stress for two generations results in a complete return to normal recombination levels, S1C1, S2C1, and $\mathrm{S} 3 \mathrm{C} 1$ plants were propagated without stress for an additional generation producing S1C2, S2C2, and S3C2 plants (Figure 2). In parallel, five generations of non-exposed control plants (C1-C5) were grown.

In most cases, HRF increased with each subsequent stressed generation of plants (S1-S5; Figures 3A-E). Single factor ANOVA showed that S1-S5 groups were significantly different from C1 to $\mathrm{C} 5$ groups for all heavy metals tested (Table A1 in Appendix). In contrast, skipping exposure to stress (S1C1, S2C1, etc.) decreased HRF, although not always to the level of the control plants (Figure 3); single factor ANOVA showed that HRF in plants that skipped one generation of exposure (S1C1, S2C1, etc.) was still significantly different from $\mathrm{C} 1$ to $\mathrm{C} 5$ groups (Table A1 in Appendix). Propagating plants without stress for a second generation (S1C2, S2C2, and S3C2) resulted in an even further decrease in HRF; single factor ANOVA revealed that HRF in these groups was similar to control groups for $\mathrm{Cd}^{2+}$ and $\mathrm{Cu}^{2+}$ but different for
Ni exposure (Table A1 in Appendix). However, we noticed that when stress exposure had occurred for two or more consecutive generations skipping stress did not substantially decrease HRF. For example, upon exposure to $50 \mathrm{mM} \mathrm{Ni}^{2+}$ the recombination frequency in continuously stressed plants was similar to the frequency in plants that skipped one generation of stress exposure (Figure 3C). However, skipping two generations of stress exposure returned HRF back to normal levels in most of the cases, with the exception of G5 plants exposed to $50 \mathrm{mM} \mathrm{Cd}^{2+}$ and G4-G5 plants exposed to $100 \mathrm{mM}$ of $\mathrm{Ni}^{2+}$.

These experiments confirmed that maintenance of high recombination frequency through a number of generations requires constant exposure to stress. They also demonstrated that the progeny of stressed plants maintain a certain "memory" of stress, even when propagated under normal conditions. This indicates that when plants are exposed to stress for more generations, the resulting stress memory is stronger and longer lasting.

\section{THE PROGENY OF PLANTS EXPOSED TO STRESS ACQUIRED TOLERANCE TO THE SAME STRESS AS WELL AS OTHER ABIOTIC STRESSES}

Our previous work showed that the progeny of plants exposed to $\mathrm{NaCl}$ or heat exhibit higher tolerance to these same stresses (Boyko et al., 2010a). To test if the progeny of plants exposed to heavy metal salts are also showed a higher stress tolerance, we exposed S1-S5 plants to high levels of heavy metal salts. Progeny of plants exposed to $\mathrm{Cu}^{2+}, \mathrm{Ni}^{2+}$, or $\mathrm{Cd}^{2+}$ were germinated and grown on $50-200 \mathrm{mM} \mathrm{Cu}^{2+}, \mathrm{Ni}^{2+}$, or $\mathrm{Cd}^{2+}$, respectively. Changes in root length represent one of the common parameters influenced by exposure to heavy metal salts (Liu et al., 2011). Measuring root length of S1-S5 plants grown on basic medium (BM) showed that the progeny of plants exposed to $\mathrm{Cu}^{2+}, \mathrm{Ni}^{2+}$, or $\mathrm{Cd}^{2+}$ had longer roots than the progeny of control plants (Figure 4). Increasing the

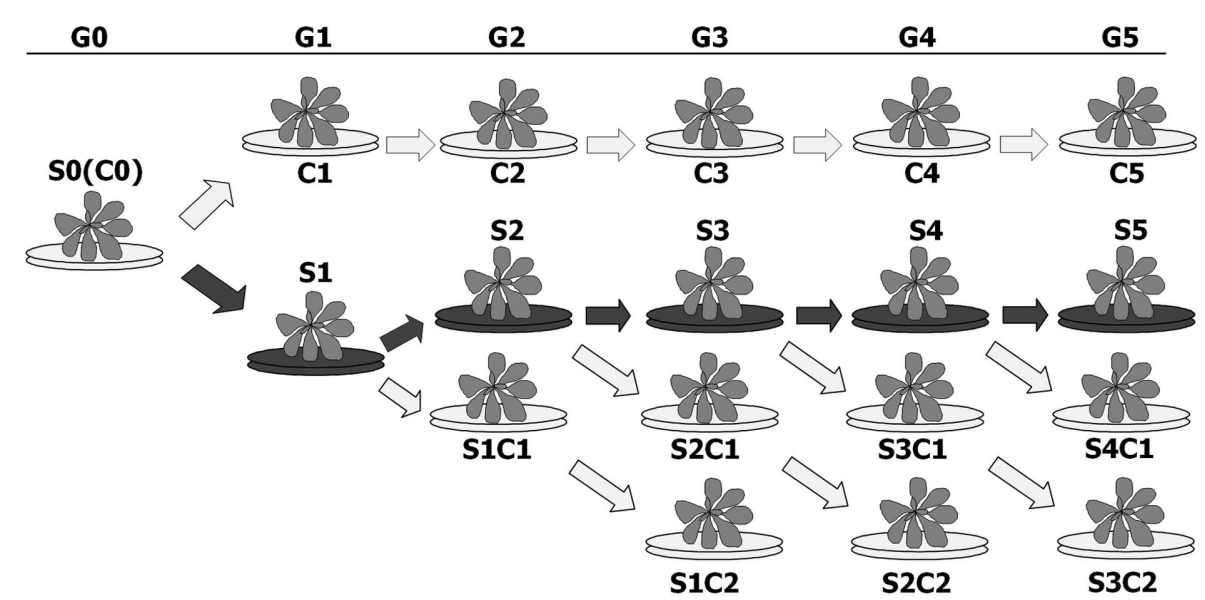

FIGURE 2 | Schematic presentation of the experiment. Plants were germinated and grown on normal MS medium (blue arrows) or MS medium supplemented with heavy metal salts (red arrows). The plants that were initially used for the experiment (G0) are labeled as SO or C0, indicating exposed and non-exposed plants. The first progeny of stressed plants (G1), labeled as S1, was then propagated to next generation (G2) in the presence or absence heavy metals, giving rise to S2 and S1C1 plants, respectively. G2 plants (S2, S1C1) were then again propagated to the next generation (G3) in presence or absence of heavy metals, giving rise to $\mathrm{S} 3, \mathrm{~S} 2 \mathrm{C} 1$, and $\mathrm{S} 1 \mathrm{C} 2$ plants. G3 plants (S3, S2C1, and S1C2) were propagated to the next generation (G4) in presence or absence of heavy metals, giving rise to $\mathrm{S} 4$, S3C1, and S2C2 plants. G4 plants (S4, S3C1, and S2C2) were propagated to the next generation (G5) in presence or absence of heavy metals, giving rise to S5, S4C1, and S3C2 plants. The control plants were propagated for five generations without stress exposure, giving rise to $\mathrm{C} 1, \mathrm{C} 2, \mathrm{C} 3, \mathrm{C} 4$, and $\mathrm{C} 5$ plants 

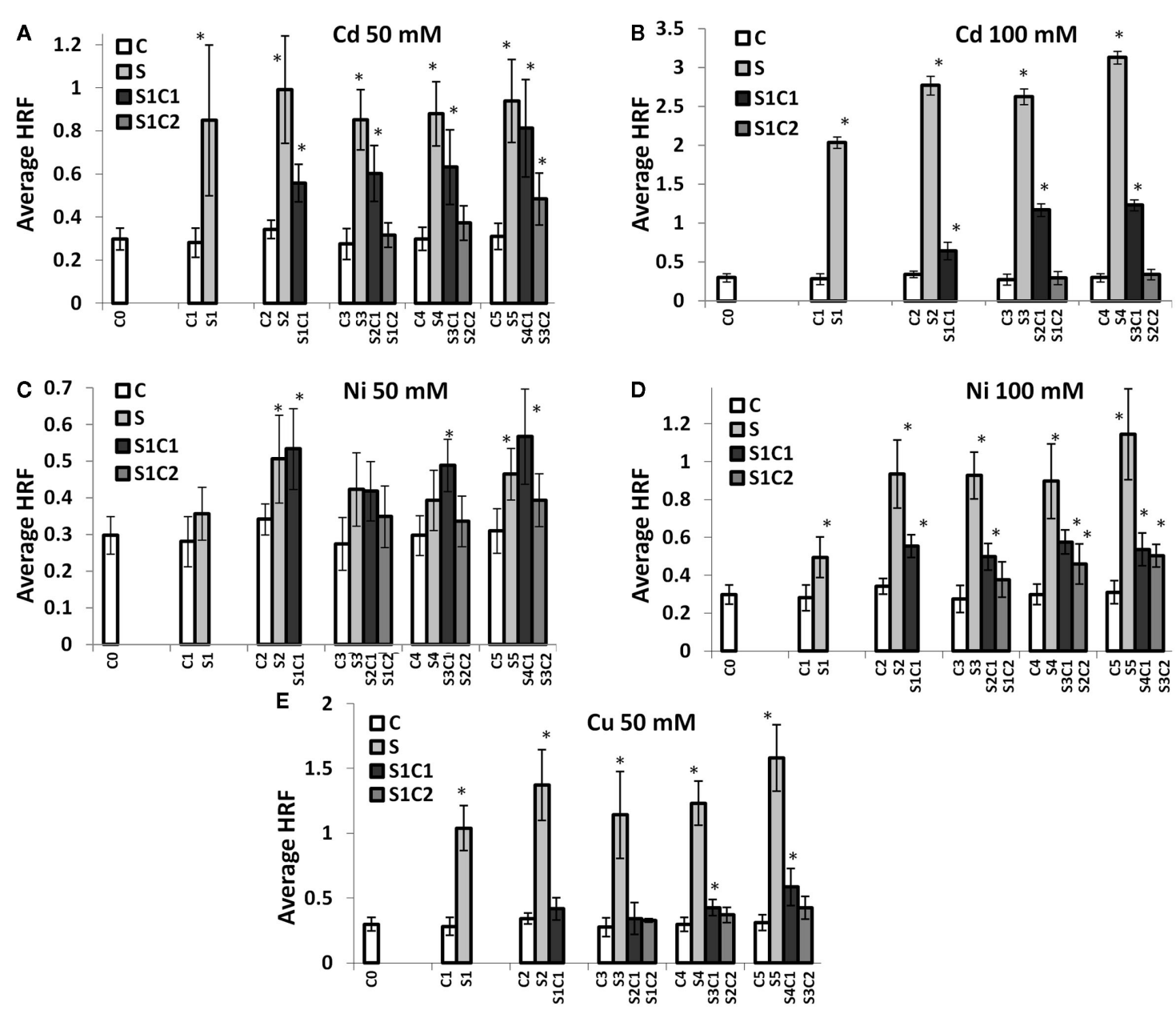

FIGURE 3 | Spontaneous HRF in the progeny of stressed plants. HRF was measured in five consecutive generations of non-exposed plants and plants exposed to $50 \mathrm{mM} \mathrm{Cd}^{2+}$ (A), $100 \mathrm{mM} \mathrm{Cd}^{2+}$ (B), $50 \mathrm{mM} \mathrm{Ni}^{2+}$ (C), $100 \mathrm{mM} \mathrm{Ni}^{2+}$ (D), and $50 \mathrm{mM} \mathrm{Cu}^{2+}$ (E). HRF was analyzed in 3-week-old plants. The vertical axis shows the average (as well as the SD) HRF calculated from three independent experiments. The horizontal axis indicates the generation, from G0 to G5. "G0" shows the HRF in somatic tissue of non-exposed plants. "G1" shows the HRF in the first progeny of control and stressed plants. "G2" shows the HRF in the second generation of control plants (ct), exposed plants (S), and plants exposed in the $\mathrm{G} 0$ and non-exposed in the G1 (S_Ct1). "G3-G5" shows the third, fourth, and fifth generations of control plants (ct), exposed plants (S), plants exposed to stress followed by growth in control conditions for one generation (S_Ct1) or two generations (S_Ct2). Asterisks indicate when there is a significant difference between the individual group of progeny of stressed and the corresponding progeny of control plants (Student's $t$-test, $p<0.05$ in all cases). No significant difference among the progeny of control (G0-G5) plants was found (Single factor ANOVA, $p>0.1$. number of generations of exposure increased root length. Analysis showed that the progeny of stressed plants have longer roots even when grown at normal conditions.

Analysis of root length in S1-S5 plants exposed to heavy metal salts demonstrated that these plants had longer roots than S0 (C0) plants or C1-C5 plants (Figure A1 in Appendix). Roots were longer in S3-S5 generations than S1-S2, and the difference between S1-S5 and S0 plants was more prominent upon exposure to a higher concentration $(200 \mathrm{mM})$ of heavy metal salt (Figure 5).

These experiments indicated that the progeny of stressed plants acquire higher tolerance to the same stress. The stress tolerance increased in progeny when the number of generations exposed to stress increased; the difference in root length was more pronounced upon exposure to harsher stresses.
To test whether S1-S5 plants are more tolerant to other abiotic stresses as well the one they had been exposed to, we exposed these plants to $\mathrm{NaCl}$ (75 and $125 \mathrm{mM}$ ) and MMS (45 and $135 \mathrm{ppm}$ ). Previous experiments showed that the highest concentration that does not significantly change plant physiology is $75 \mathrm{mM} \mathrm{NaCl}$, whereas $125 \mathrm{mM} \mathrm{NaCl}$ results in severe growth inhibition (Boyko et al., 2010b). Similarly, exposure to 45 ppm MMS normally does not change plant physiology dramatically, whereas a concentration of $135 \mathrm{ppm}$ is lethal or nearly lethal (Yao et al., 2010). The analysis of root length in plants exposed to $\mathrm{NaCl}$ showed that roots were longer in the progeny of stressed plants, a difference that was more severe as a result of exposure to $125 \mathrm{mM}$ than to $75 \mathrm{mM}$ $\mathrm{NaCl}$ (Figure 6). Performing the same analysis in plants exposed to 45 ppm MMS showed that S1-S5 plants had longer roots than S0 plants (Figure 7). There was once again a tendency toward longer 

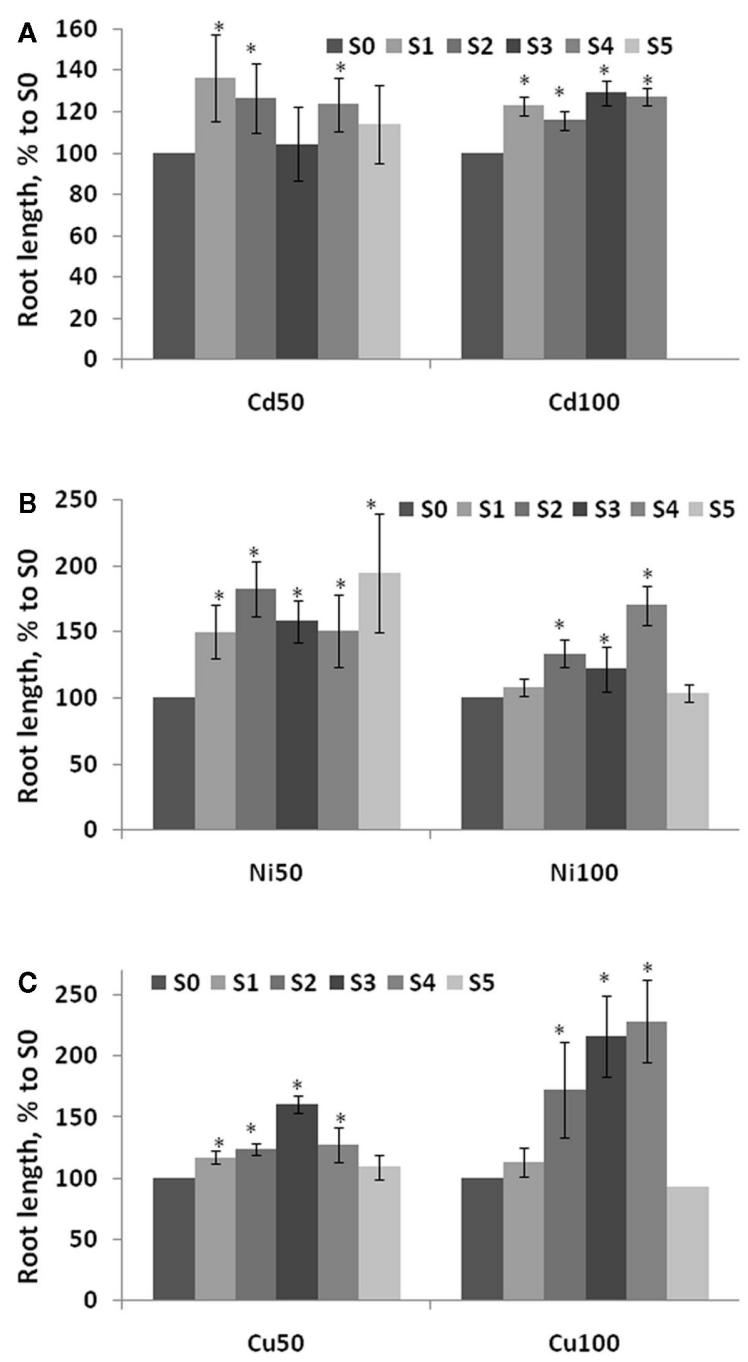

FIGURE 4 | Root length in the progeny of stressed plants. Root length was measured in five consecutive generations of plants exposed to 50 and $100 \mathrm{mM} \mathrm{Cd}^{2+}$ (A), 50 and $100 \mathrm{mM} \mathrm{Ni}^{2+}$ (B), and 50 and $100 \mathrm{mM} \mathrm{Cu}^{2+}$ (C) as well as non-exposed plants. Plants were germinated and grown on normal MS medium and roots were measured at 2 weeks post-germination. The vertical axis indicates the average (with $\mathrm{SD}$, calculated from three different experiments) root length in S1-S5 plants shown as percentage difference to the root length in S0 plants. Asterisks show when there is a significant difference between the individual groups of S1-S5 plants and S0 plants (Student's $t$-test, $p<0.05$ in each case).

roots in S3-S5 plants in comparison to S1-S2 plants. Root length in $\mathrm{C} 0-\mathrm{C} 5$ plants exposed to $\mathrm{NaCl}$ or $\mathrm{MMS}$ was similar regardless of generation (Figure A1 in Appendix). Exposure to $135 \mathrm{ppm}$ MMS resulted in severe growth inhibition and the majority of plants either did not germinate or died at the cotyledon stage, not allowing for any meaningful comparison.

\section{DISCUSSION}

The experiments reported here demonstrated the following: plants exposed to three different heavy metals exhibited increased HRF in somatic tissue; the progeny of stressed plants had higher HRF; exposure to stress for multiple generations maintained the high recombination frequency, whereas skipping the exposure to stress resulted in the tendency of returning HRF to normal; skipping exposure to heavy metals after several generations of exposure resulted in a higher "residual" increase in recombination frequency; the progeny of stressed plants exhibited higher tolerance to the same stress as well as to $\mathrm{NaCl}$ and MMS.

The highest HRF increase in the progeny was observed upon exposure to $100 \mathrm{mM} \mathrm{CdCl}_{2}$. This is in contrast to the response of somatic tissue where the highest increase was observed upon exposure to $\mathrm{Cu}^{2+}$. The lowest increase of HRF in progeny and somatic tissue was observed upon exposure to $\mathrm{NiCl}_{2}$. Previous reports have shown that exposure to viral and bacterial pathogens (Lucht et al., 2002; Kovalchuk et al., 2003; Kathiria et al., 2010), pathogenic determinant flagellin (Molinier et al., 2005), $\mathrm{NaCl}$, temperature, and water stress (Boyko et al., 2010a,b) as well as UVB and UVC (Ries et al., 2000; Molinier et al., 2005; Boyko et al., 2010a) all resulted in a transgenerational HRF increase. In contrast, the work of Pecinka et al. (2009) demonstrated that transgenerational increases in recombination frequency are not a common response to stress; only 4 out of 10 tested stresses and stress compositions lead to the HRF increase in the progeny (Pecinka et al., 2009).

Previous work has also found changes in HRF in response to multiple generations of exposure to stress. Molinier et al. (2006) showed that a single generation of UVC stress triggered an HRF increase that lasted for five subsequent generations (Molinier et al., 2005). In contrast, our previous work showed that propagation of plants exposed to stress for a single generation resulted in the return of HRF to normal levels when grown under normal conditions (Boyko et al., 2010a). Our current work demonstrated that an increased HRF for five generations only when each generation was obtained upon propagation of plants in presence of stress. The recombination frequency returned to normal or nearly normal levels when plants were propagated without stress exposure for one or two generations (Figure 3). Plants propagated at normal conditions for two generations had HRF lower than those propagated without stress for only one generation. Interestingly, when plants were grown under normal conditions following several generations of exposure to stress (S3-S5), HRF remained high in the non-exposed progeny.

From these results, it can be hypothesized that the normal stress response of an organism includes both a physiological response as well as transmission of information about the stress to its immediate progeny. When a second generation is grown in normal conditions, the absence of the stress-dependent signal does not allow these plants to pass the information to the next generation. However, when stress is present for two or more generations, the stress-dependent signal may "last" longer and be passed on even without stress, resulting in changes in future generations. Still, propagation without stress for two generations decreases the strength of the signal dramatically. In fact the HRF in the progeny of plants propagated without stress for two generations, following multiple generations with stress, was reduced to nearly normal levels. Observed changes in recombination frequency and stress tolerance suggest that this stress-induced signal may be epigenetic in nature. 


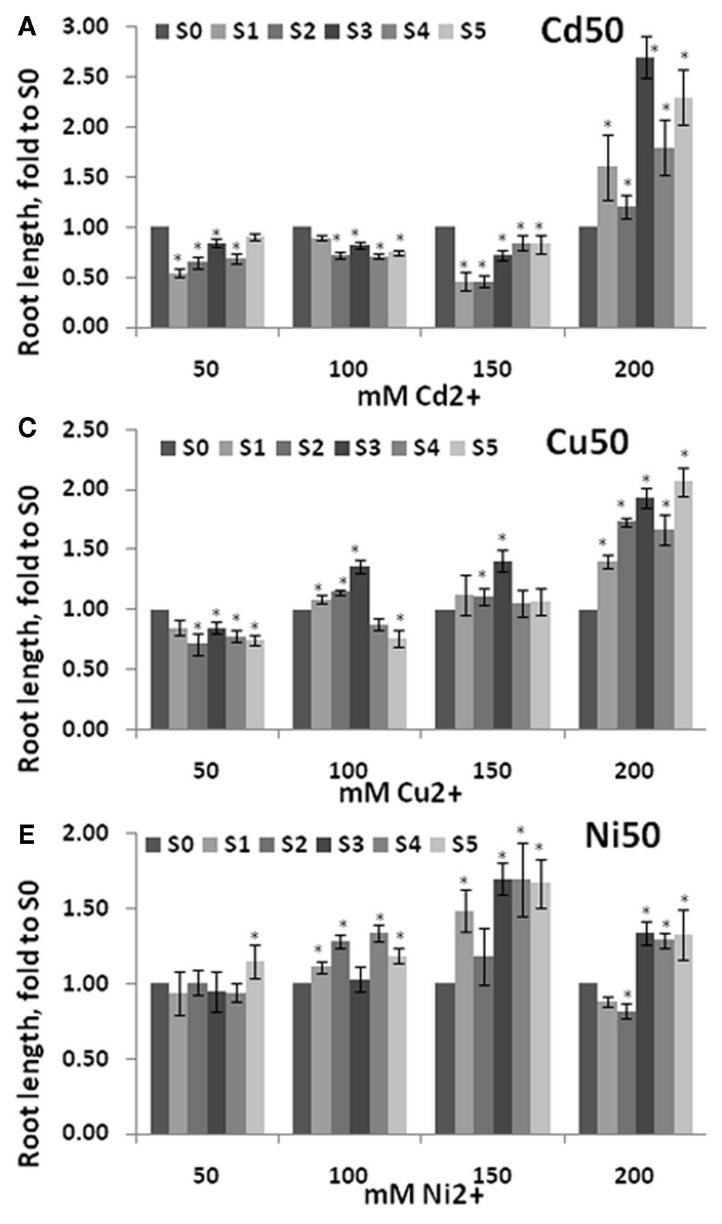

FIGURE 5 | Root length in the progeny of stressed plants exposed to high concentration of heavy metals. Root length was measured in five consecutive generations of non-exposed plants and plants exposed to $50 \mathrm{mM}$ $\mathrm{Cd}^{2+}$ (A), $100 \mathrm{mM} \mathrm{Cd}^{2+}$ (B), $50 \mathrm{mM} \mathrm{Cu}^{2+}$ (C), $100 \mathrm{mM} \mathrm{Cu}^{2+}$ (D), $50 \mathrm{Ni}^{2+}$ (E), and $100 \mathrm{mM} \mathrm{Ni}^{2+}$ (F). Plants were germinated and grown on MS medium supplemented with 50,100,150, and $200 \mathrm{mM}$ of respective heavy metal salt,
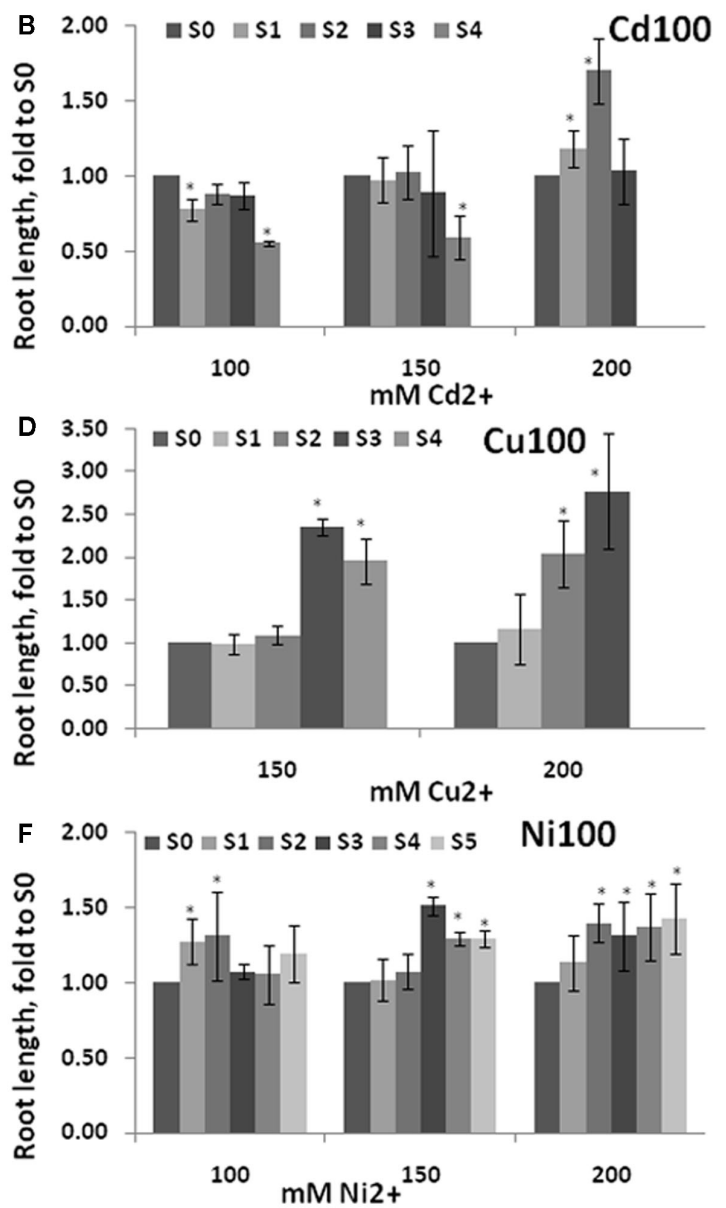

i.e., Progeny of plants exposed to $\mathrm{Cd}^{2+}$ were grown on various concentrations of $\mathrm{Cd}^{2+}$. Roots were measured at 2 weeks post-germination. The vertical axis shows the average (with SD, calculated from three different experiments) root length in S1-S5 plants shown as percentage difference to the root length in So plants. Asterisks indicate a significant difference between the individual groups of S1-S5 plants and S0 plants (Student's $t$-test, $p<0.05$ in each case).
Plant gametes are produced from somatic cells late during development, thus allowing the information accumulated during plant growth to be passed to the progeny (Paszkowski and Grossniklaus, 2011). Plants undergo reprogramming of DNA methylation and histone modifications in gametes as well as the developing embryo. Inheritance of a stress-induced epigenetic signal may depend on changes in DNA methylation and histone modifications (Boyko and Kovalchuk, 2011a,b; Ito et al., 2011). Reprogramming of these changes may limit plant's capacity to pass information onto the progeny. Reprogramming of the plant genome involves a substantially lower level of demethylation than that of the animal genome (Paszkowski and Grossniklaus, 2011) suggesting that plants may have a higher capacity for transmission of epigenetic changes to the progeny. It is currently unclear what the nature of epigenetic stress-induced signal seen in this study is. However, it can be hypothesized that the initial signal may be a certain type of small non-coding RNA, presumably siRNAs (Ito et al., 2011). Differentially expressed siRNAs may promote changes in DNA methylation and associated histone modifications, which are then transmitted to progeny. Although the role of histones and histone variants in transgenerational signaling may not be obvious, they cannot be excluded (Ingouff et al., 2010).

That progeny of stressed plants have a higher tolerance to the same as well as other stresses is also very interesting. Previous reports have shown that progeny of plants exposed to various stresses also exhibit stress tolerance, (Whittle et al., 2009; Boyko et al., 2010a; Kathiria et al., 2010) often to a broad spectrum of stresses, suggesting that transgenerational inheritance involves general stress protection mechanisms. Indeed, we previously demonstrated that progeny of stressed plants have a higher capacity for DNA repair and exhibit changes in the level of various metabolites (Boyko et al., 2010a; Kathiria et al., 2010; Yao and Kovalchuk, 2011; Kathiria and Kovalchuk, in review). Lack of specificity in stress response is perhaps not surprising considering that many stress-induced miRNAs and siRNAs have a broad spectrum of action. For example, they may be involved in 

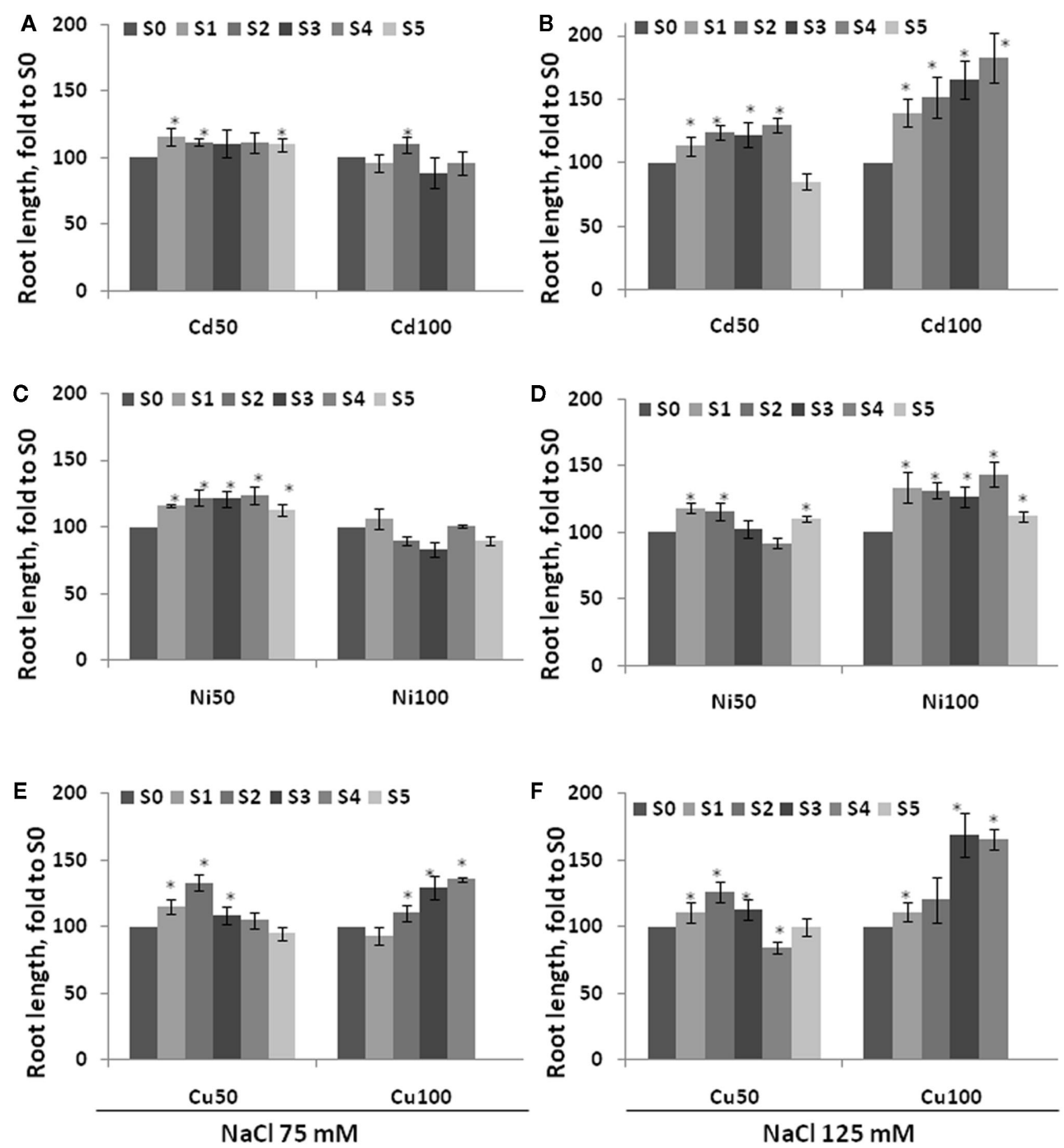

FIGURE 6 | Root length in the progeny of stressed plants exposed to high concentration of $\mathrm{NaCl}$. Root length was measured in five consecutive generations of non-exposed plants and plants exposed to $50 \mathrm{mM} \mathrm{Cd}^{2+}$ or $100 \mathrm{mM} \mathrm{Cd}^{2+}(\mathbf{A}, \mathbf{B}), 50 \mathrm{Ni}^{2+}$ or $100 \mathrm{mM} \mathrm{Ni}^{2+}$ (C,D), $50 \mathrm{mM} \mathrm{Cu}^{2+}$ or $100 \mathrm{mM} \mathrm{Cu}^{2+}(\mathbf{E}, \mathbf{F})$. Plants were germinated and grown on $\mathrm{MS}$ medium supplemented with $75 \mathrm{mM} \mathrm{NaCl}(\mathbf{A}, \mathbf{C}, \mathbf{E})$ and $125 \mathrm{mM} \mathrm{NaCl}$

$(\mathbf{B}, \mathbf{D}, \mathbf{F})$ and roots were measured at 2 weeks post-germination. The vertical axis indicates the average (with SD, calculated from three different experiments) root length in S1-S5 plants shown as percentage difference to the root length in SO plants. Asterisks show when there is a significant difference between the individual group of S1-S5 plants and S0 plants (Student's $t$-test, $p<0.05$ in each case).

response to oxidative stress, signaling, and epigenetic regulation. Previous research shows a significant overlap in changes of small RNA expression in response to salt and UV stress (Zhou et al., 2007, 2008). It remains to be shown if exposure to different stresses not only changes the expression of similar sets of ncRNAs but also leads to similar changes in DNA methylation and histone modifications in somatic cells and gametes. Furthermore, it remains to be established whether some of these changes can be observed in somatic cells of the progeny of stressed plants.

\section{MATERIALS AND METHODS \\ PLANTS USED FOR THE EXPERIMENTS}

Arabidopsis thaliana plants line \#11 were used in the experiments. Plants carry in the genome a single copy of GUS-based homologous recombination substrate (Swoboda et al., 1994; Ilnytskyy et al., 2004). The recombination substrate consists of two overlapping non-functional copies of truncated $\beta$-glucuronidase transgene. Recombination between the two regions of homology results in restoration of the functional transgene. Cells in which transgene is activated appear as blue dots/sectors visualized by histochemical staining.

\section{EXPERIMENTAL SET-UP}

Arabidopsis thaliana plants line \#11 were germinated and grown on control MS medium or MS medium supplemented with 50 or $100 \mathrm{mM}$ of $\mathrm{CuCl}_{2}, \mathrm{CdCl}_{2}$, or $\mathrm{NiCl}_{2}$ heavy metal salts. Each plate contained 70-80 plants and each experimental group was represented by three to five plates. Three weeks after germination, 20 
randomly chosen plants from each plate were transplanted to soil. Plants were grown at $12 \mathrm{~h} \mathrm{day} / 12 \mathrm{~h}$ night conditions at $22^{\circ} \mathrm{C}$ with illumination at $100 \mu \mathrm{M} \mathrm{m}^{-2} \mathrm{~s}^{-1}$. Exposed plants are referred to as "S0," for "stressed, G0," whereas non-exposed plants are "C0," for "control, G0." Seeds of exposed and control plants were referred to as "S1" and "C1," for "stressed, G1" and "control, G1," respectively. "S1" plants stemming from exposure to $\mathrm{Cu}^{2+}, \mathrm{Ni}^{2+}$, or $\mathrm{Cd}^{2+}$ were then again grown in control MS medium or MS medium supplemented with $\mathrm{CuCl}_{2}, \mathrm{CdCl}_{2}$, or $\mathrm{NiCl}_{2}$; seeds of these plants were collected and referred to as "S1C1" and "S2," respectively. "S2" plants were then propagated in presence of heavy metal salts for three more generations, giving rise to "S3," "S4," and "S5" plants (Figure 2). "S2", "S3," and "S4" plants were also propagated without stress, giving rise to "S2C1", "S3C1," and "S4C1" plants. "S1C1", "S2C1," and "S3C1" were also propagated without stress for one more generation, giving rise to "S1C2", "S2C2," and "S3C2" plants. Control plants were propagated on normal MS medium for five generations, resulting in $\mathrm{C} 1, \mathrm{C} 2, \mathrm{C} 3, \mathrm{C} 4$, and $\mathrm{C} 5$ plants. In each case, seeds were pooled from 20 plants per each treatment. Three biological repeats per treatment were performed.

\section{ANALYSIS OF HOMOLOGOUS RECOMBINATION FREQUENCY}

Homologous recombination frequency in Arabidopsis plants was analyzed following histochemical staining as previously described (Boyko et al., 2006). Recombination events were scored in a population of approximately 200 plants per experimental group, and HRF was calculated by comparing the number of recombination events to the total number of plants scored. Each experiment was repeated three times.

\section{ANALYSIS OF PLANT ADAPTATION}

For the analysis of acquired stress tolerance the progeny of exposed and non-exposed plants were germinated and grown on 50$200 \mathrm{mM} \mathrm{Cu}^{2+}, \mathrm{Ni}^{2+}$, or $\mathrm{Cd}^{2+}$ or 75 and $125 \mathrm{mM} \mathrm{NaCl}$ or 45 and 135 ppm MMS. Root length was measured using 20 plants per each plate, three plates per treatment and was performed 2 weeks after germination. The experiments were repeated three times.

\section{STATISTICAL TREATMENT OF THE DATA}

In all cases, mean and SE were calculated. The statistical significance of the experiments was confirmed by either a Student's $t$-test (two-tailed paired or non-paired) or a Single factor ANOVA for each individual heavy metal group (between all C1-C5 and S1S5, between C2-C5 and all S1C1 groups, between C3-C5 and all $\mathrm{S} 1 \mathrm{C} 2$ groups, between S2-S5 and S1C1 groups, between S3-S5 and S1C2 groups as well as between S1C1 and S1C2 groups; Table A1 in Appendix). Statistical analyses were performed using the MS Excel software and Microcal Origin 6.0.

\section{REFERENCES}

Aina, R., Sgorbati, S., Santagostino, A., Labra, M., Ghiani, A., and Citterio, S. (2004). Specific hypomethylation of DNA is induced by heavy metals in white clover and industrial hemp. Physiol. Plant 121, 472-480.

Bollmann, S. R., Tominey, C. M., Hoffman, P. D., Hoffman, T. M., and Hays, J. B. (2011). Reversionreporter transgenes to analyze all six base-substitution pathways in Arabidopsis. Plant Physiol. 155, 1286-1300.

Bourc'his, D., and Voinnet, O. (2010). A small-RNA perspective on gametogenesis, fertilization, and early zygotic development. Science 330, 617-622.

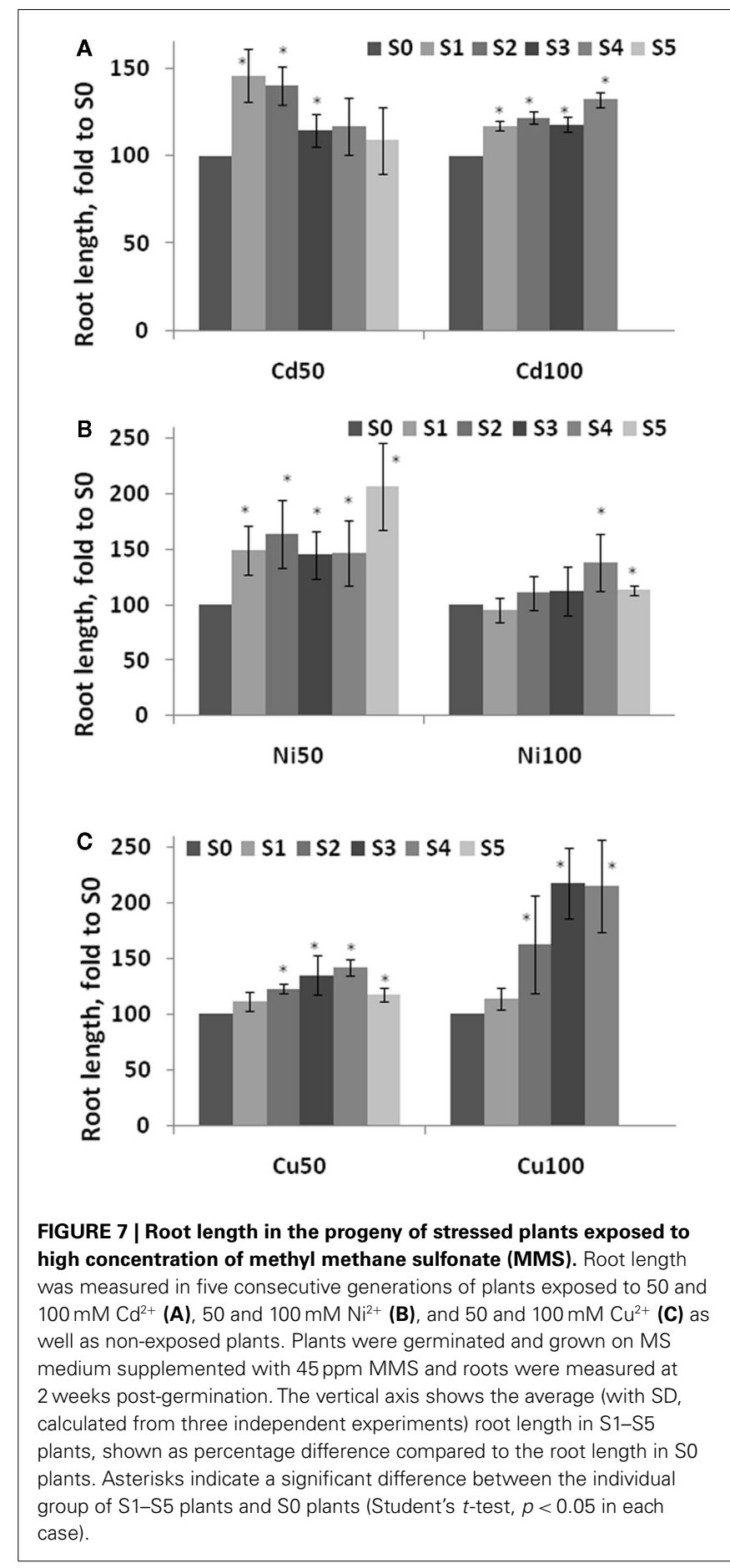

Boyko, A., Blevins, T., Yao, Y., Golubov, A., Bilichak, A., Ilnytskyy, Y., Hollunder, J., Meins, F. Jr., and Kovalchuk, I. (2010a). Transgenerational adaptation of Arabidopsis to stress requires DNA methylation and the function of Dicer-like proteins. PLOS ONE 5, e9514. doi:10.1371/journal.pone. 0009514
Boyko, A., Golubov, A., Bilichak, A., and Kovalchuk, I. (2010b). Chlorine ions but not sodium ions alter genome stability of Arabidopsis thaliana. Plant Cell Physiol. 51, 1066-1078.

Boyko, A., and Kovalchuk, I. (2008). Epigenetic control of plant stress response. Environ. Mol. Mutagen. 49, 61-72. 
Boyko, A., and Kovalchuk, I. (2010). Transgenerational response to stress in Arabidopsis thaliana. Plant Signal. Behav. 5, 995-998.

Boyko, A., and Kovalchuk, I. (2011a). Genetic and epigenetic effects of plant-pathogen interactions: an evolutionary perspective. Mol. Plant 4, 1014-1023.

Boyko, A., and Kovalchuk, I. (2011b). Genome instability and epigenetic modification-heritable responses to environmental stress? Curr. Opin. Plant Biol. 14, 260-266.

Boyko, A., Zemp, F., Filkowski, J., and Kovalchuk, I. (2006). Double-strand break repair in plants is developmentally regulated. Plant Physiol. 141, 488-497.

Carthew, R. W., and Sontheimer, E. J. (2009). Origins and mechanisms of miRNAs and siRNAs. Cell 136, 642-655.

Chitwood, D. H., Nogueira, F. T., Howell, M. D., Montgomery, T. A., Carrington, J. C., and Timmermans, M. C. (2009). Pattern formation via small RNA mobility. Genes Dev. 23, 549-554.

De Block, M., and Van Lijsebettens, M. (2011). Energy efficiency and energy homeostasis as genetic and epigenetic components of plant performance and crop productivity. Curr. Opin. Plant Biol. 14, 275-282.

Dunoyer, P., Schott, G., Himber, C., Meyer, D., Takeda, A., Carrington, J. C., and Voinnet, O. (2010). Small RNA duplexes function as mobile silencing signals between plant cells. Science 328, 912-916.

Filkowski, J., Yeoman, A., Kovalchuk, O., and Kovalchuk, I. (2004). Systemic plant signal triggers genome instability. Plant J. 38, 1-11.

Grant-Downton, R., Le Trionnaire, G., Schmid, R., Rodriguez-Enriquez, J., Hafidh, S., Mehdi, S., Twell, D., and Dickinson, H. (2009). MicroRNA and tasiRNA diversity in mature pollen of Arabidopsis thaliana. BMC Genomics 10, 643. doi:10.1186/1471-2164-10-643

Hauser, M. T., Aufsatz, W., Jonak, C., and Luschnig, C. (2011). Transgenerational epigenetic inheritance in plants. Biochim. Biophys. Acta 1809, 459-468.

Ilnytskyy, Y., Boyko, A., and Kovalchuk, I. (2004). Luciferase-based transgenic recombination assay is more sensitive than beta-glucoronidasebased. Mutat. Res. 559, 189-197.

Ingouff, M., Rademacher, S., Holec, S., Soljic, L., Xin, N., Readshaw, A., Foo, S. H., Lahouze, B., Sprunck, S., and Berger, F. (2010). Zygotic resetting of the histone 3 variant repertoire participates in epigenetic reprogramming in Arabidopsis. Curr. Biol. 20, 2137-2143.

Ito, H., Gaubert, H., Bucher, E., Mirouze, M., Vaillant, I., and Paszkowski, J. (2011). An siRNA pathway prevents transgenerational retrotransposition in plants subjected to stress. Nature 472, 115-119.

Kathiria, P., Sidler, C., Golubov, A., Kalischuk, M., Kawchuk, L. M., and Kovalchuk, I. (2010). Tobacco mosaic virus infection results in an increase in recombination frequency and resistance to viral, bacterial, and fungal pathogens in the progeny of infected tobacco plants. Plant Physiol. 153, 1859-1870.

Kovalchuk, I., Kovalchuk, O., Kalck, V., Boyko, V., Filkowski, J., Heinlein, M., and Hohn, B. (2003). Pathogeninduced systemic plant signal triggers DNA rearrangements. Nature 423, 760-762.

Kovalchuk, O., Arkhipov, A., Barylyak, I., Karachov, I., Titov, V., Hohn, B., and Kovalchuk, I. (2000). Plants experiencing chronic internal exposure to ionizing radiation exhibit higher frequency of homologous recombination than acutely irradiated plants. Mutat. Res. 449, 47-56.

Labra, M., Ghiani, A., Citterio, S., Sgorbati, S., Sala, F., Vannini, C., RuffiniCastiglione, M., and Bracale, M. (2002). Analysis of cytosine methylation pattern in response to water deficit in pea root tips. Plant Biol. 4, 694-699.

Lang-Mladek, C., Popova, O., Kiok, K., Berlinger, M., Rakic, B., Aufsatz, W., Jonak, C., Hauser, M. T., and Luschnig, C. (2010). Transgenerational inheritance and resetting of stress-induced loss of epigenetic gene silencing in Arabidopsis. Mol. Plant 3, 594-602.

Liu, G. Y., Zhang, Y. X., and Chai, T. Y. (2011). Phytochelatin synthase of Thlaspi caerulescens enhanced tolerance and accumulation of heavy metals when expressed in yeast and tobacco. Plant Cell Rep. 30, 1067-1076.

Lucht, J. M., Mauch-Mani, B., Steiner, H. Y., Metraux, J. P., Ryals, J., and Hohn, B. (2002). Pathogen stress increases somatic recombination frequency in Arabidopsis. Nat. Genet. 30, 311-314.

Malone, C. D., and Hannon, G. J. (2009). Small RNAs as guardians of the genome. Cell 136, 656-668.

Mason, G., Noris, E., Lanteri, S., Acquadro, A., Accotto, G. P., and Portis, E. (2008). Potentiality of methylation-sensitive amplification polymorphism (MSAP) in identifying genes involved in tomato response to tomato yellow leaf curl
Sardinia virus. Plant Mol. Biol. Rep. 26, 156-173.

Mirouze, M., and Paszkowski, J. (2011). Epigenetic contribution to stress adaptation in plants. Curr. Opin. Plant Biol. 14, 267-274.

Molinier, J., Oakeley, E. J., Niederhauser, O., Kovalchuk, I., and Hohn, B. (2005). Dynamic response of plant genome to ultraviolet radiation and other genotoxic stresses. Mutat. Res. 571, 235-247.

Molinier, J., Ries, G., Zipfel, C., and Hohn, B. (2006). Transgeneration memory of stress in plants. Nature 442, 1046-1049.

Molnar, A., Melnyk, C. W., Bassett, A., Hardcastle, T. J., Dunn, R., and Baulcombe, D. C. (2010). Small silencing RNAs in plants are mobile and direct epigenetic modification in recipient cells. Science 328 872-875.

Mosher, R. A., Melnyk, C. W., Kelly, K. A., Dunn, R. M., Studholme, D J., and Baulcombe, D. C. (2009). Uniparental expression of PolIVdependent siRNAs in developing endosperm of Arabidopsis. Nature 460, 283-286.

Paszkowski, J., and Grossniklaus, U. (2011). Selected aspects of transgenerational epigenetic inheritance and resetting in plants. Curr. Opin. Plant Biol. 14, 195-203.

Pecinka, A., Rosa, M., Schikora, A., Berlinger, M., Hirt, H., Luschnig, C., and Mittelsten Scheid, O. (2009). Transgenerational stress memory is not a general response in Arabidopsis. PLoS ONE 4, e5202. doi:10.1371/journal.pone.0005202

Ries, G., Heller, W., Puchta, H., Sandermann, H., Seidlitz, H. K., and Hohn, B. (2000). Elevated UV-B radiation reduces genome stability in plants. Nature 406, 98-101.

Roy, S. J., Tucker, E. J., and Tester, M. (2011). Genetic analysis of abiotic stress tolerance in crops. Curr. Opin. Plant Biol. 14, 232-239.

Saze, H. (2008). Epigenetic memory transmission through mitosis and meiosis in plants. Semin. Cell Dev. Biol. 19, 527-536.

Slotkin, R. K., Vaughn, M., Borges, F., Tanurdzic, M., Becker, J. D., Feijo, J. A., and Martienssen, R. A. (2009). Epigenetic reprogramming and small RNA silencing of transposable elements in pollen. Cell 136, 461-472.

Swoboda, P., Gal, S., Hohn, B., and Puchta, H. (1994). Intrachromosomal homologous recombination in whole plants. EMBO J. 13, 484-489.

Van Der Auwera, G., Baute, J., Bauwens, M., Peck, I., Piette, D., Pycke,
M., Asselman, P., and Depicker, A. (2008). Development and application of novel constructs to score C:G-to-T:A transitions and homologous recombination in Arabidopsis. Plant Physiol. 146, 22-31.

Whittle, C. A., Otto, S. P., Johnston, M. O., and Krochko, J. E. (2009). Adaptive epigenetic memory of ancestral temperature regime in Arabidopsis thaliana. Botany 87, 650-657.

Wilkinson, S., and Davies, W. J. (2010). Drought, ozone, ABA and ethylene: new insights from cell to plant to community. Plant Cell Environ. 33, 510-525.

Yao, Y., Bilichak, A., Golubov, A., Blevins, T., and Kovalchuk, I. (2010). Differential sensitivity of Arabidopsis siRNA biogenesis mutants to genotoxic stress. Plant Cell Rep. 29, 1401-1410.

Yao, Y., and Kovalchuk, I. (2011). Abiotic stress leads to somatic and heritable changes in homologous recombination frequency, point mutation frequency and microsatellite stability in Arabidopsis plants. Mutat. Res. 707, 61-66.

Zhou, X., Wang, G., Sutoh, K., Zhu, J. K., and Zhang, W. (2008). Identification of cold-inducible microRNAs in plants by transcriptome analysis. Biochim. Biophys. Acta 1779, 780-788.

Zhou, X., Wang, G., and Zhang, W. (2007). UV-B responsive microRNA genes in Arabidopsis thaliana. Mol. Syst. Biol. 3, 103.

Conflict of Interest Statement: The authors declare that the research was conducted in the absence of any commercial or financial relationships that could be construed as a potential conflict of interest.

Received: 03 September 2011; accepted: 15 November 2011; published online: 05 December 2011.

Citation: Rahavi MR, Migicovsky Z, Titov V and Kovalchuk I (2011) Transgenerational adaptation to heavy metal salts in Arabidopsis. Front. Plant Sci. 2:91. doi: 10.3389/fpls.2011.00091

This article was submitted to Frontiers in Plant Genetics and Genomics, a specialty of Frontiers in Plant Science.

Copyright (c) 2011 Rahavi, Migicovsky, Titov and Kovalchuk. This is an openaccess article distributed under the terms of the Creative Commons Attribution Non Commercial License, which permits non-commercial use, distribution, and reproduction in other forums, provided the original authors and source are credited. 


\section{APPENDIX}

Table A1 | Statistical analysis of HRF using single factor ANOVA.

\begin{tabular}{|c|c|c|c|c|}
\hline Ni 50 & C & $\mathbf{S}$ & S1C1 & S1C2 \\
\hline C & $x$ & & & \\
\hline S & 0.002 & $x$ & & \\
\hline $\mathrm{S} 1 \mathrm{C} 1$ & 0.001 & 0.225 & $x$ & \\
\hline $\mathrm{S} 1 \mathrm{C} 2$ & 0.031 & 0.067 & 0.047 & $x$ \\
\hline $\mathrm{Ni} 100$ & C & S & S1C1 & $\mathrm{S} 1 \mathrm{C} 2$ \\
\hline C & $x$ & & & \\
\hline$S$ & 0.0002 & $x$ & & \\
\hline $\mathrm{S} 1 \mathrm{C} 1$ & 3.55E-05 & 0.0003 & $x$ & \\
\hline $\mathrm{S} 1 \mathrm{C} 2$ & 0.017 & 0.003 & 0.104 & $x$ \\
\hline Cd 50 & C & $\mathrm{S}$ & S1C1 & $\mathrm{S} 1 \mathrm{C} 2$ \\
\hline $\mathrm{C}$ & $x$ & & & \\
\hline $\mathrm{S}$ & 4.13E-08 & $x$ & & \\
\hline $\mathrm{S} 1 \mathrm{C} 1$ & 0.001 & 0.006 & $x$ & \\
\hline $\mathrm{S} 1 \mathrm{C} 2$ & 0.127 & 0.0008 & 0.024 & $x$ \\
\hline Cd 100 & C & $\mathrm{S}$ & S1C1 & $\mathrm{S} 1 \mathrm{C} 2$ \\
\hline C & $x$ & & & \\
\hline S & 4.95E-05 & $x$ & & \\
\hline $\mathrm{S} 1 \mathrm{C} 1$ & 0.019 & 0.002 & $x$ & \\
\hline $\mathrm{S} 1 \mathrm{C} 2$ & 0.320 & 0.010 & 0.002 & $x$ \\
\hline Cu50 & C & S & S1C1 & $\mathrm{S} 1 \mathrm{C} 2$ \\
\hline C & $x$ & & & \\
\hline S & 7.24E-06 & $x$ & & \\
\hline $\mathrm{S} 1 \mathrm{C} 1$ & 0.043 & 0.0002 & $x$ & \\
\hline $\mathrm{S} 1 \mathrm{C} 2$ & 0.057 & 0.002 & 0.374 & $x$ \\
\hline
\end{tabular}

" $C$ " represents HRF in C1-C5 plants, " $S$ " represents HRF in S1-S5 groups, "S1C1" represents HRF in S1C1, S2C1, S3C1, and S4C1 groups, whereas "S1C2" represents data for S1C2, S2C2, and S3C2 groups. Numbers in bold indicate signficant difference.

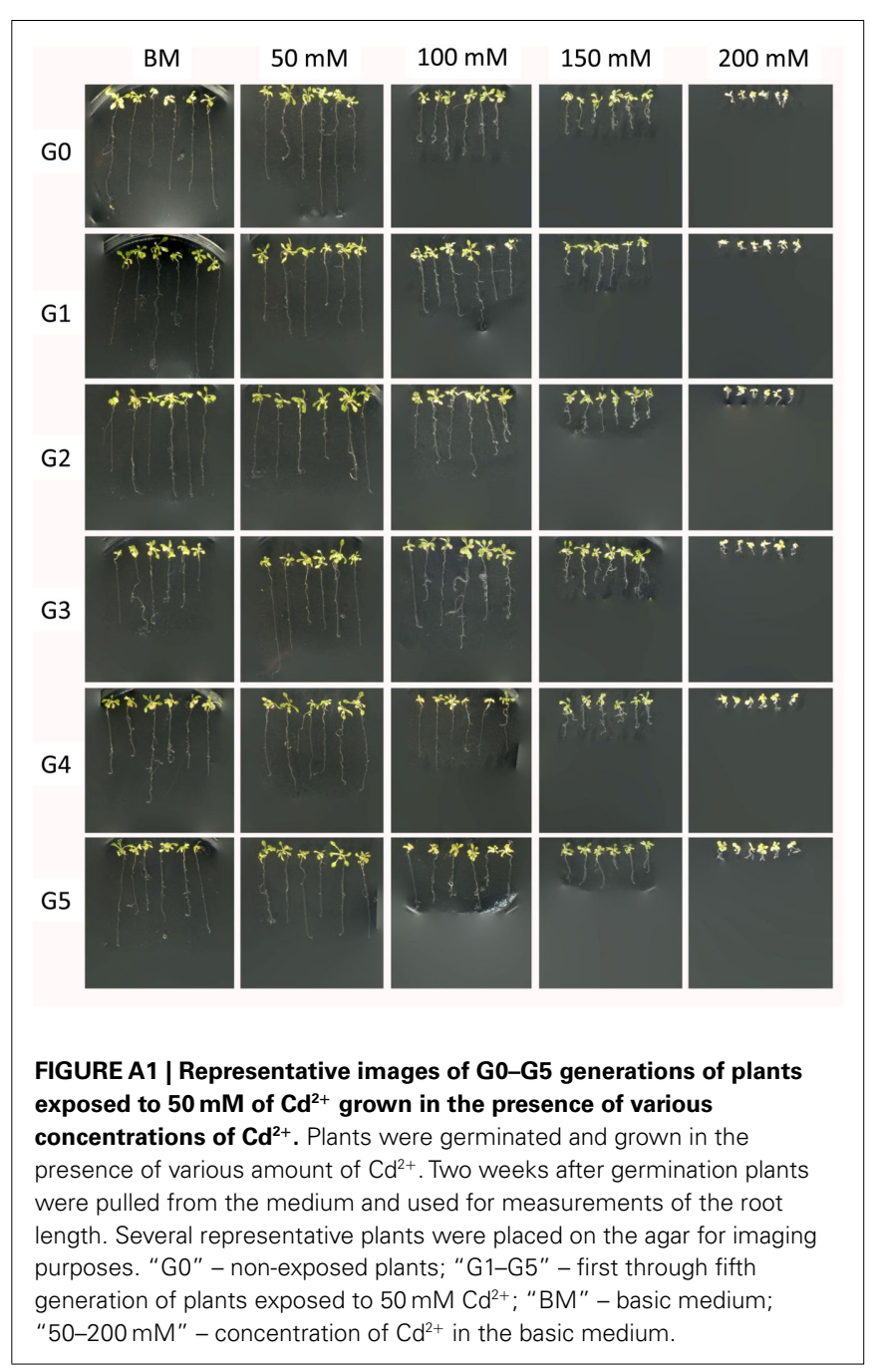

